\title{
Coronary artery stenting in unstable angina pectoris: a comparison with stable angina pectoris
}

\author{
P B M Clarkson, M Halim, K K Ray, S Doshi, M Been, H Singh, M F Shiu
}

\begin{abstract}
Objective-To compare early complication rates in unselected cases of coronary artery stenting in patients with stable $v$ unstable angina.

Setting-Tertiary referral centre.

Patients-390 patients with stable angina pectoris (SAP) and 306 with unstable angina (UAP). Patients treated for acute myocardial infarction (primary angioplasty) or cardiogenic shock were excluded.

Interventions-268 coronary stents were attempted in 211 patients $(30.3 \%)$. Stents used included AVE (63\%), Freedom (14\%), NIR (7\%), Palmaz-Schatz (5\%), JO (5\%), and Multilink (4\%). Intravascular ultrasound was not used in any of the cases. All stented patients were treated with ticlopidine and aspirin together with periprocedural unfractionated heparin.

Results-123 stents were successfully deployed in 99 SAP patients $v 132$ stents in 103 UAP patients. Failed deployment occurred with nine stents in SAP patients, $v$ four in UAP patients (NS). Stent thrombosis occurred in four SAP patients and 11 UAP patients. Multivariate analysis showed no relation between stent thrombosis and clinical presentation (SAP $v$ UAP), age, sex, target vessel, stent length, or make of stent. Stent thrombosis was associated with small vessel size $(\mathrm{p}<0.001)$ and bailout stenting $(\mathrm{p}=0.01)$ compared with elective stenting and stenting for suboptimal PTCA, with strong trends toward smaller stent diameter $(p=0.052)$ and number of stents deployed $(p=0.06)$. Most stent thromboses occurred in vessels $<3 \mathrm{~mm}$ diameter.

Conclusions-Coronary artery stenting in unstable angina is safe in vessels $\geqslant 3 \mathrm{~mm}$ diameter, with comparable initial success and stent thrombosis rates to stenting in stable angina.

(Heart 1999;81:393-397)
\end{abstract}

Cardiology, Walsgrave

Hospital, Clifford

Bridge Road, Coventry

CV2, UK

P B M Clarkson

M Halim

K K Ray

S Doshi

M Been

H Singh

M F Shiu

Correspondence to: Dr Clarkson.

email: pbclarkson@aol.com

Accepted for publication 1 October 1998

Keywords: angina pectoris; stents

Coronary artery stenting in stable angina pectoris has become a widely accepted procedure in managing both vessel closure ${ }^{12}$ and suboptimal results ${ }^{34}$ after conventional balloon angioplasty (percutaneous transluminal coronary angioplasty, PTCA). Moreover in certain patient groups elective intracoronary stent implantation is more effective than simple PTCA alone. ${ }^{5}$ In stented vessels there is a low incidence of early vessel closure (stent thrombosis), ${ }^{6}$ and lower restenosis rates than with conventional PTCA. ${ }^{7}$ Acute coronary syndromes (acute myocardial infarction and unstable angina pectoris) are commonly associated with intracoronary thrombus. ${ }^{8}{ }^{9}$ In these patients there are concerns about the use of intracoronary stents, and in particular about the risks of acute and subacute stent thrombosis. ${ }^{1011}$ There is, however, a paucity of data comparing the results of stent implantation in patients with stable and unstable angina pectoris. The available studies give conflicting results, some suggesting an increased subacute stent thrombosis rate in unstable angina, ${ }^{10} 12$ but others suggesting there is no difference between stable and unstable angina. ${ }^{13}$ In this study we compare the rates of stent thrombosis and mortality in a group of consecutive unselected patients with stable or unstable angina pectoris.

\section{Methods}

PATIENTS

Details about the patients are given in table 1 . Between January 1996 and December 1996, coronary artery stenting was attempted in 211 (30.3\%) of 696 consecutive coronary angioplasties performed for stable or unstable angina in our cardiac catheterisation laboratory. Our hospital has an immediate catchment of 325000 , and receives angioplasty referrals for a further 375000 . In all, 220 coronary vessels were stented, after 268 attempts; 99 of these patients were treated for stable angina and 103 for unstable angina (unstable angina was defined as angina at rest within the previous 72 hours). Seventeen of the vessels stented were saphenous vein bypass grafts. No internal mammary grafts were stented. Our study excluded all cases of primary angioplasty and salvage angioplasty for patients with acute myocardial infarction, and all patients with cardiogenic shock at the time of entry to the catheterisation laboratory. All patients were followed up for at least one month after stent implantation.
STENTING PROCEDURE

Lesion specific stenting was applied in all cases, with the majority of stents being AVE (63.5\%), Freedom (14.1\%), NIR (7.1\%), PalmazSchatz $(4.7 \%)$, and JO (4.7\%). Smaller numbers of Multilink (4.3\%), ACT1 $(0.8 \%)$, Wiktor $(0.4 \%)$, and Wallstents were implanted $(0.4 \%)$. Choice of stent was determined by user preference, lesion length, vessel diameter, and tortuosity of the vessel. Angioplasty and coronary stent deployment were performed using standard techniques. Stent deployment 
Table 1 Patient details

\begin{tabular}{lcc}
\hline & $\begin{array}{c}\text { Stable } \\
\text { angina }\end{array}$ & $\begin{array}{c}\text { Unstable } \\
\text { angina }\end{array}$ \\
\hline Patients (n) & 99 & 103 \\
Vessels (n) & 105 & 115 \\
Stents (n) & 123 & 132 \\
Failed stents (n) & 9 & 4 \\
Sex (M/F) & $81 / 18$ & $80 / 23$ \\
Mean (SD) age (years) & $61.8(9.4)$ & $61.2(11.2)$ \\
Mean (SD) vessel diameter (mm) & $3.2(0.4)$ & $3.3(0.5)$ \\
Mean (SD) stent diameter (mm) & $3.3(0.4)$ & $3.3(0.3)$ \\
LAD stents (n) & 43 & 46 \\
RCA stents (n) & 36 & 41 \\
Cx stents (n) & 16 & 18 \\
Left main stem stents (n) & 3 & 0 \\
Saphenous vein graft stents (n) & 7 & 10 \\
\hline
\end{tabular}

$\mathrm{Cx}$, circumflex coronary artery; LAD, left anterior descending coronary artery; RCA, right coronary artery.

was classified as bailout in situations of actual or threatened vessel closure, suboptimal in cases with a suboptimal result after balloon angioplasty (that is, limited dissection not threatening vessel closure, elastic recoil, or residual stenosis $\geqslant 20 \%$ ), and elective in patients in whom stent deployment was planned from the outset of the angioplasty procedure. All patients received oral aspirin (75-300 $\mathrm{mg}$ ) before the start of the procedure. After insertion of the arterial sheath an intra-arterial bolus of $10000 \mathrm{IU}$ of heparin was given (a 5000 IU bolus in patients who were being treated with intravenous heparin at the start of the procedure). Additional 5000 IU intra-arterial boluses of heparin were given every hour throughout the angioplasty/stenting procedure. All lesions were predilated before stenting. Stents were either premounted or hand crimped on to the angioplasty balloon catheter. Final dilatation of the stent was performed with a balloon estimated to achieve a balloon to normal artery ratio of $1: 1$. No stents were deployed in vessels smaller than 2.5 $\mathrm{mm}$ diameter.

All the procedures were performed with high quality digital radiographic equipment. Final dilatation of the stent was performed either at nominal pressure or at high inflation pressures ( $>12$ atmospheres) to ensure optimal deployment. Intravascular ultrasound (IVUS) was not used in any case.

After the procedure an intravenous heparin infusion was begun $(1250 \mathrm{IU} / \mathrm{h})$ for a minimum period of 12 hours. The femoral sheaths were removed four to six hours after the discontinuation of heparin. Ticlopidine (250 mg twice daily) was started immediately after the procedure and continued for a period of one month under clinical monitoring. One patient was withdrawn from ticlopidine owing to skin reaction and started on oral anticoagulant treatment.

ANGIOGRAPHIC ANALYSIS

Vessel diameter was calculated predominantly using "eyeball" assessment and in cases of dispute the automated edge detection system, which is part of the digital cineangiographic system. Calibration was done using the $7 \mathrm{~F}$ guiding catheter before contrast injection. Measurement of the reference vessel diameter was made at the proximal part of the vessel nearest the stenosis except in ostial or bifurcational lesions, where the nearest normal vessel distal to the stenosis was measured.

\section{STATISTICAL ANALYSIS}

All analyses were analysed by use of the Statgraphics software package. Data are expressed as means (SD). A multivariate analysis was performed to determine the predictors of stent thrombosis, taking $p<0.05$ as significant. The factors used in this analysis were age, sex, operator, vessel stented, number of vessels stented, vessel diameter, stent diameter, stent indication (bailout $v$ suboptimal result $v$ elective), clinical presentation, number of stents implanted, stent length, make of stent, and maximum stent inflation pressure (high $v$ nominal).

\section{Results}

The results are summarised in table 2 and figs $1-3$.

\section{DEMOGRAPHICS}

Demographic information is given in table 1: $80 \%$ of the patients were male; mean age was 61.4 years; mean vessel diameter was $3.3 \mathrm{~cm}$. Most stents were implanted into either the left anterior descending coronary artery (LAD) or the right coronary artery (RCA), with fewer into circumflex, left main stem, or vein graft lesions (fig 2). There were no significant differ-

Table 2 Stent implantation and thrombosis

\begin{tabular}{llc}
\hline & $\begin{array}{l}\text { Stable } \\
\text { angina }(n)\end{array}$ & $\begin{array}{l}\text { Unstable } \\
\text { angina }(n)\end{array}$ \\
\hline Stent indication & 20 & 2 \\
$\quad$ Elective & 62 & 80 \\
Suboptimal & 17 & 21 \\
Bailout & & \\
Stent type & 81 & 81 \\
AVE & 10 & 8 \\
NIR & 13 & 23 \\
Freedom & 6 & 6 \\
Palmaz-Schatz & 6 & 6 \\
JO & 7 & 8 \\
Other & 4 & 11 \\
Stent thrombosis & 1 & 3 \\
Death & & \\
\hline
\end{tabular}

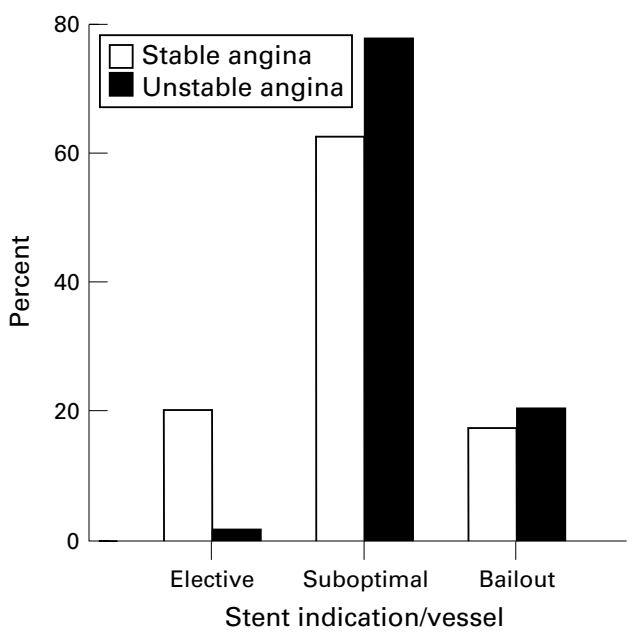

Figure 1 Percentages of stents deployed for elective, suboptimal, and bailout indications in patients with stable and unstable angina pectoris. 


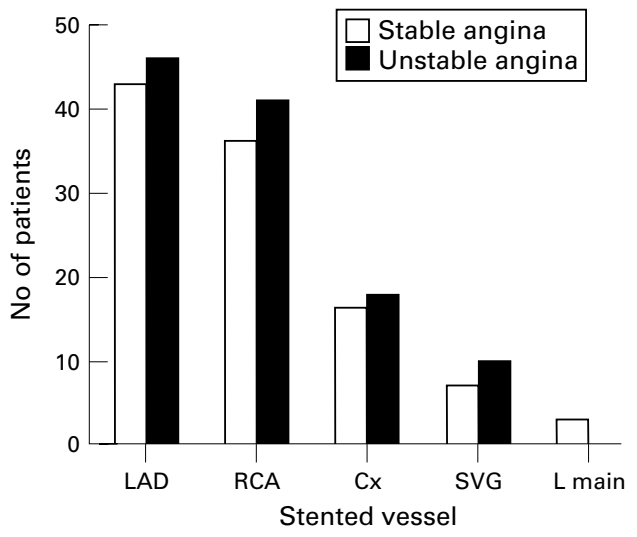

Figure 2 Number of vessels in which stent implantation was performed, separated by vessel type in stable and unstable angina pectoris. LAD, left anterior descending coronary artery (including diagonal lesions); RCA, right coronary artery; $\mathrm{Cx}$, circumflex coronary artery (including obtuse marginal lesions); $S V G$, saphenous vein graft; $L$ main, left main stem artery (all protected by previous coronary surgery).

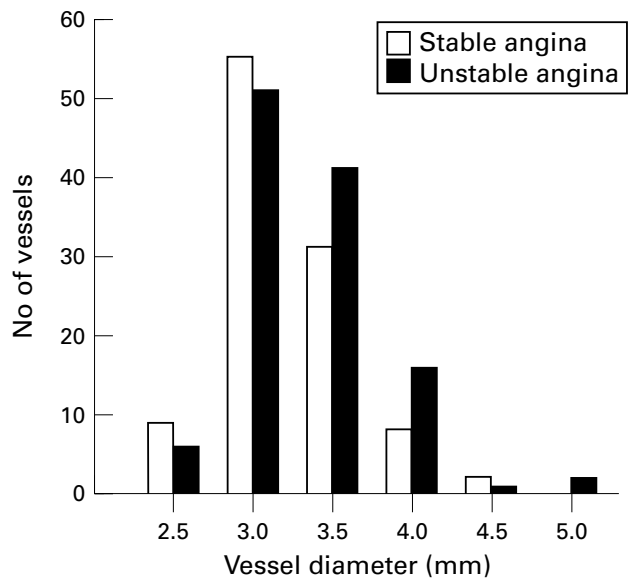

Figure 3 Diameter of vessels stented in patients with stable and unstable angina pectoris.

ences between sex, age, vessel or stent diameter (fig 3), or vessel treated between stable and unstable patients.

STENT IMPLANTATION

Intracoronary stents were deployed electively in 22 patients (two unstable $v 20$ stable), as bailout in 38 patients ( 21 unstable $v 17$ stable), and for a suboptimal angioplasty result in the remaining 142 patients (80 unstable $v 62$ stable). Thirteen stents failed to be deployed and were either withdrawn (4), lost into the peripheral circulation (5), or became stuck in the proximal coronary arteries (4, with three patients requiring emergency coronary bypass grafting). There was no significant difference between stable and unstable angina in terms of failed stent deployment. More stents were deployed electively in patients with stable angina $(\mathrm{p}<0.05)$.

STENT THROMBOSIS

In all, 15 patients developed stent thrombosis, four with stable angina and 11 with unstable angina (12 male and three female patients, mean (SD) age 61.5 (6.8) years). Stent thrombosis occurred a mean of 81 (96) hours after stent implantation (range four hours to 14 days). Two patients died as a result of stent thrombosis.

PREDICTORS OF STENT THROMBOSIS

Using the multivariate regression model described above, significant predictors of stent thrombosis were smaller vessel size $(\mathrm{p}<0.001)$ and indication for stent implantation (bailout $v$ suboptimal $v$ elective) $(\mathrm{p}=0.014)$. Nonsignificant trends towards increased stent thrombosis were also observed with smaller stent diameter $(p=0.052)$, greater number of stents implanted $(\mathrm{p}=0.06)$, lower maximum inflation pressure $(\mathrm{p}=0.08)$, and with unstable presentation $(\mathrm{p}=0.12)$.

\section{STABLE $v$ UNSTABLE ANGINA}

Predictors for stent thrombosis were different in the two groups of patients. In patients with stable angina the only predictors of stent thrombosis were lower maximum inflation pressure $(p=0.02)$ and greater number of vessels stented $(p=0.03)$, whereas in patients with unstable angina the predictors were smaller vessel diameter $(\mathrm{p}=0.001)$, indication for stent implantation ( $\mathrm{p}=0.012)$, stent diameter $(p=0.02)$, and greater number of stents implanted $(\mathrm{p}=0.03)$.

\section{DEATH}

Four patients $(2.0 \%)$ died during or up to one month after stent implantation; in two, death was secondary to stent thrombosis. The only significant predictor of death in the multivariate model was the indication for stent implantation ( $\mathrm{p}=0.012)$ - that is, bailout $v$ suboptimal $v$ elective. Three deaths occurred in bailout stents compared with one suboptimal result stent.

\section{REPEAT REVASCULARISATION}

No patient had repeat PTCA performed in the month following stent implantation except for those described above with stent thrombosis. In one patient with successful stent deployment for unstable angina coronary artery bypass grafting was performed in the follow up period.

\section{Discussion}

Since the first description of intracoronary stent implantation in $1987^{14}$ there has been considerable interest in factors predisposing to stent thrombosis, and in methods of preventing it. The majority of studies, however, have been in selected population groups, and may not, therefore, reflect general clinical scenarios. We examined an unselected group of consecutive patients with almost equal proportions of unstable and stable angina. The rate of stent thrombosis was $7.4 \%$ of all stenting procedures. The rate in stable angina was $3.8 \%$, compared with $10.7 \%$ in unstable angina. This figure is in agreement with pooled data analysis, which estimates the rate of stent thrombosis in emergency situations to be $10.1 \%$ and in elective situations to be $4.3 \% .{ }^{6}$ Our rate of stent thrombosis does, however, appear high compared with other recent publications, which estimate the 
rate of subacute stent thrombosis to be of the order of $3.4 \%{ }^{15}$ to $5 \% .^{716}$ We feel that our overall rate reflects an unselected population with a high proportion of unstable patients. It thus included several high risk patients who would not have been entered into randomised trails. Most recent trials evaluating stent thrombosis only included haemodynamically stable patients with discrete lesions ( $<15 \mathrm{~mm}$ length) in non-tortuous vessels $>3.0 \mathrm{~mm}$ diameter, and without intraluminal thrombus or involvement of bifurcation or ostium (for example, the Benestent trial). ${ }^{71517}$ Other groups have shown a greater incidence of stent thrombosis during elective angioplasty in types of patient not enrolled in the Benestent study. ${ }^{18}$ If we simply excluded similar smaller vessels from the analysis then our rate of stent thrombosis would be reduced to $5.9 \%$.

We found a higher rate of subacute stent thrombosis in patients with unstable angina than in stable angina. After multivariate regression analysis, however, the clinical presentation only had a weak, non-significant interaction with the development of stent thrombosis. The factors predisposing to stent thrombosis, in descending order, were smaller vessel size, bailout stenting, smaller stent diameter, and greater number of stents implanted. In the light of previous data on the high risk of stent thrombosis in small arteries, ${ }^{1161920}$ all operators had a high threshold for stent implantation in these patients, and hence the numbers are small in our dataset ( $6.8 \%$ of all vessels stented were $\sim 2.5 \mathrm{~mm}$ in diameter). Stent thrombosis developed in $26.7 \%$ of the vessels $<3.0 \mathrm{~mm}$ in diameter, and although there was no significant difference in the number of patients with $2.5 \mathrm{~mm}$ vessels between the groups with stable and unstable angina, the risks of stent thrombosis were particularly high in the unstable group $(50 \% v 11.1 \%)$. It is generally thought that the high rate of stent thrombosis relates to lower blood flow and a greater percentage of metal to lumen area. It is likely that in this group the presence of thrombus, which is commonly found in unstable angina, ${ }^{89}$ acts as a further nidus for the formation of occlusive intraluminal thrombus.

It is well recognised that bailout stenting results in more stent thrombosis than elective stenting. ${ }^{102122}$ It is accepted that there is a highly thrombotic intravascular environment in the situation of acute or threatened vessel closure, relating to vessel wall dissection, subintimal haemorrhage, vasoconstriction, low blood flow, and activation of both platelets and coagulation factors. ${ }^{23}$ In our dataset the rates of bailout stenting and stenting for suboptimal results were greater in patients with unstable angina. In the cohort overall, $18.4 \%$ of bailout stents subsequently thrombosed, compared with $6.3 \%$ of suboptimal stents and no elective stents. In patients with stable angina the rates were $11.8 \%, 4.8 \%$, and $0 \%$ respectively, compared with $23.8 \%, 7.5 \%$, and $0 \%$ in those with unstable angina. We feel that this at least partially explains the higher stent thrombosis rate in patients with unstable angina.
We found no relation between the length of the stent and the development of stent thrombosis, but a weak relation with greater numbers of stents implanted. There is very little information on either of these variables from reports of controlled studies. It is thought that greater length or number of stents may be more thrombogenic; one study showed a weak relation between stent length and stent thrombosis, ${ }^{1}$ other studies have not confirmed this. ${ }^{2}{ }^{1522}{ }^{24}$ It is probable that multiple stenting is performed in longer lesions or longer dissections and therefore there is a greater underlying substrate for the development of intraluminal thrombus.

Stents from different manufacturers differ with respect to materials, strut diameters, lattice size, radial strength, and flexibility. Despite this we found no significant differences between the eight types of stent used during the course of this study with respect to stent thrombosis. Thrombosis occurred in $6.8 \%$ of all AVE stent implants, $5.6 \%$ of Freedom stents, $5.6 \%$ of NIR stents, $16.7 \%$ of PalmazSchatz stents, and not at all in the other stent types (presumably owing to the low numbers of those stents being deployed). No randomised controlled study has yet been performed with different stent types, but available data seem to suggest that there is little effect of stent make on the likelihood of stent thrombosis. ${ }^{625}$

The risk of stent thrombosis for LAD lesions was $11.2 \%$, right coronary artery lesions $6.5 \%$, circumflex lesions $0 \%$, vein graft lesions $5.9 \%$, and left main stem lesions $0 \%$. These differences were not statistically significant in our study, but show similar trends to previous data which suggested that the risk of thrombosis was greatest in LAD lesions. ${ }^{26}$ The reason for this is unclear, although it could reflect more frequent deployment as a bailout procedure. ${ }^{27}$ In our patient population this was not the case; indeed the rate of stenting for bailout was $22 \%$ among LAD lesions compared with $23 \%$ in other vessels. This suggests that the increased stent thrombosis rate in LAD lesions may be related to other factors - for example, a less streamlined blood flow because of the increased number of branches and the greater tortuosity of this artery.

There was a weak (non-significant) relation between thrombosis and maximum stent inflation pressure. In all, $2.5 \%$ of stents that were inflated to high pressure ( $\geqslant 12$ atmospheres) subsequently thrombosed, compared with $8 \%$ of stents inflated only to nominal pressure. Recent studies using intravascular ultrasound have raised concerns over the adequacy of stent deployment at nominal balloon inflation pressures. Goldberg et al, using intravascular ultrasound imaging, found that only $12.5 \%$ of patients had complete stent deployment despite adequate angiographic findings. ${ }^{28}$ In view of this, many operators are now either deploying all stents at high pressure ${ }^{29}$ or using a combined intravascular ultrasound and balloon catheter approach. ${ }^{30}$ 
In all, four patients died within one month of intracoronary stent implantation, two as a direct result of stent thrombosis. The only variable having a predictive value for death was bailout stenting. Our rate of death following stent thrombosis (13.3\%) compares with pooled data from numerous trials which suggest a rate of $12 \% .^{6}$

In summary, we found that the risk of subacute stent thrombosis is increased in unstable angina pectoris. In multivariate analysis, however, unstable angina was no longer significant as a predictor of stent thrombosis, which was principally related to stenting in small arteries and for bailout indications. The higher stent thrombosis rate in unstable angina can therefore be explained by factors other than the presentation alone. The rate of stent thrombosis was particularly high in patients with unstable angina who had stents deployed in small vessels $(\sim 2.5 \mathrm{~mm})$ or as a bailout procedure. Subacute stent thrombosis often occurs after hospital discharge ${ }^{101526}$ and is associated with a high mortality. ${ }^{6}$ Other treatments-for example, alternative antithrombotic regimens such as glycoprotein IIb/IIIa receptor antagonists (abciximab), should be investigated in the subset of patients at particularly high risk of stent thrombosis.

We would like to thank Benia Csaza for her assistance in collecting the data.

1 Roubin GS, Cannon AD, Agrawal SK, et al. Intracoronary stenting for acute and threatened closure complicating per-
cutaneous transluminal coronary angioplasty. Circulation 1992;85:916-27.

2 Herrman HC, Buchbinder M, Clemen MW, et al. Emergent use of balloon-expandable coronary artery stenting for failed percutaneous transluminal coronary angioplasty. Circulation 1992;86:812-9.

3 Sutton JM, Ellis SG, Roubin GS, et al. Major clinical events after coronary stenting. The multicenter registry of acute after coronary stenting. The multicenter registry of acute 1994;89:1126-37.

4 Haude E, Erbel R, Straub U, et al. Results of intracoronary stents for management of coronary dissection after balloon angioplasty. Am F Cardiol 1991;67:691-6.

5 Versaci F, Gaspardone A, Tomai F, et al. A comparison of coronary-artery stenting with angioplasty for isolated stenosis of the proximal left anterior descending coronary artery. N Engl $\mathcal{f}$ Med 1997;336:817-22.

6 Mak K-HM, Belli G, Ellis SG, et al. Subacute stent thrombosis: evolving issues and current concepts. $\mathcal{F} \mathrm{Am} \mathrm{Coll}$ Cardiol 1996;27:494-503.

7 Serruys PW, de Jaegere P, Kiemeneij F, et al. A comparison of balloon-expandable-stent implantation with balloon angioplasty in patients with coronary artery disease. $N E n g l$ f Med 1994;331:489-95.

8 Mizuno K, Satomura K, Miyamoto A, et al. Angioscopic evaluation of coronary artery thrombi in acute coronary evaluation of coronary artery thrombi in acur

9 DeWood GW, Spores J, Notske R, et al. Prevalence of total coronary occlusion during the early hours of transmural coronary occlusion during the early hours of transmural
myocardial infarction. $N$ Engl F Med 1980;303:897-902.
10 Nath FC, Muller DWM, Ellis SG, et al. Thrombosis of a flexible coil coronary stent: frequency, predictors and clinical outcome. I Am Coll Cardiol 1993;21:622-7.

11 Shaknovich A. Complications of coronary stenting. Coron Artery Dis 1994;5:583-9.

12 Malosky SA, Hirshfield JWJ, Hermann HC. Comparison of results of intracoronary stenting in patients with unstable vs. stable angina. Cathet Cardiovasc Diagn 1994;31:95-101.

13 Robinson NMK, Thomas MR, Wainwright RJ, et al. Unstable angina is not a contraindication to intracoronary stent insertion [abstract]. F Invas Cardiol 1995;7:6A.

14 Sigwart U, Puel J, Mirkovitch V, et al. Intravascular stents to prevent occlusion and restenosis after transluminal angioplasty. N Engl f Med 1987;316:701-6.

15 Fischman DL, Leon MB, Baim DS, et al. A randomised comparison of coronary-stent placement and balloon angioplasty in the treatment of coronary artery disease. $N$ Engl $\mathcal{F}$ Med 1994;331:496-501.

16 George BS, Voorhees WD, Roubin GS, et al. Multicenter investigation of coronary stenting to treat acute or threatened closure after percutaneous transluminal coronary angioplasty: clinical and angiographic outcome. $7 \mathrm{Am}$ Coll Cardiol 1993;22:135-42.

17 Penn IM, Brown RI, Almond D, et al. Stent thrombosis remains the major early limitation in elective stenting: inhospital and six week outcome of TASC I [abstract]. Circulation 1994;90(suppl I):I-650.

18 Williams IL, Thomas MR, DeBelder A, et al. In-patient outcome and clinical restenosis in Benestent and nonBenestent lesions [abstract]. Heart 1997;77(suppl 1):46.

19 Serruys PW, Strauss BH, Beatt KJ, et al. Angiographic follow-up after placement of a self-expanding coronaryartery stent. $N$ Engl F Med 1991;324:13-17.

20 Liu MW, Voorhees WD, Agrawal S, et al. Stratification of the risk of thrombosis after intracoronary stenting for threatened or acute closure complicating balloon angioplasty: a Cook registry study. Am Heart f 1995;130:8-13.

21 Haude M, Erbel R, Issa H, et al. Subacute thrombotic complications after intracoronary implantation of PalmazSchatz stents. Am Heart f 1993;126:15-22.

22 Foley JB, Brown RIG, Penn IM. Thrombosis and restenosis after stenting in failed angioplasty: comparison with elective stenting. Am Heart f 1994;128:12-20.

23 Block PC, Myler RK, Stenzer S, et al. Morphology after transluminal angioplasty in human beings. $N$ Engl $7 \mathrm{Med}$ 1981;305:382-5.

24 Colombo A, Goldberg SL, Almagor Y, et al. A novel strategy for stent deployment in the treatment of acute or threatened closure complicating balloon coronary angioplasty. Use of short or standard (or both) single or multiple Palmaz-Schatz stents. F Am Coll Cardiol 1993;22:188791.

25 MacIsaac AI, Ellis SG, Muller DW, et al. Comparison of three coronary stents: clinical and angiographic outcome after elective placement in 134 patients. Cathet Cardiovasc Diagn 1994;33:199-204.

26 Schomig A, Kastragi A, Mudra H, et al. Four-year experience with Palmaz-Schatz stenting in coronary angioplasty complicated by dissection with threatened or present vessel closure. Circulation 1994;90:2716-24.

27 Eeckout E, Stauffer J-C, Vogt P, et al. Can early closure and restenosis following endoluminal stenting be predicted from clinical and angiographic variables at the time of intervention? [abstract]. F Invas Cardiol 1995;7:7A.

28 Goldberg SL, Colombo A, Nakamura S, et al. Benefit of intracoronary ultrasound in the deployment of PalmazSchatz stents. F Am Coll Cardiol 1994;24:996-1003.

29 Caputo RP, Lopez JJ, Ho KKL, et al. Intravascular ultrasound analysis of routine high pressure post-dilatation after Palmaz-Schatz deployment [abstract]. $\mathcal{F}$ Am Coll Cardiol 1995;25:49A.

30 Mudra H, Klauss V, Blasini R, et al. Ultrasound guidance of Palmaz-Schatz intracoronary stenting with a combined intravascular ultrasound balloon catheter. Circulation 1994; 90:1252-61. 